Etnográfica

Revista do Centro em Rede de Investigação em

Antropologia

vol. 17 (1) | 2013

Vol. $17(1)$

\title{
A prevalência da lógica integracionista: negações à perícia antropológica em processos criminais do Tribunal de Justiça do Mato Grosso do Sul
}

The prevalence of an integrationist logic: denials of anthropological assessment on criminal cases of the justice court of Mato Grosso do Sul

Simone Becker, Olivia Carla Neves de Souza e Jorge Eremites de Oliveira

\section{(2) OpenEdition}

\section{Journals}

\section{Edição electrónica}

URL: https://journals.openedition.org/etnografica/2580

DOI: 10.4000/etnografica.2580

ISSN: 2182-2891

\section{Editora}

Centro em Rede de Investigação em Antropologia

Edição impressa

Data de publição: 1 fevereiro 2013

Paginação: 97-120

ISSN: 0873-6561

Refêrencia eletrónica

Simone Becker, Olivia Carla Neves de Souza e Jorge Eremites de Oliveira, «A prevalência da lógica integracionista: negações à perícia antropológica em processos criminais do Tribunal de Justiça do Mato Grosso do Sul», Etnográfica [Online], vol. 17 (1) | 2013, posto online no dia 13 março 2013, consultado o 10 fevereiro 2022. URL: http://journals.openedition.org/etnografica/2580 ; DOI: https:// doi.org/10.4000/etnografica.2580

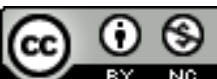

Etnográfica is licensed under a Creative Commons Attribution-NonCommercial 4.0 International License. 


\section{A prevalência da lógica integracionista: negações à perícia antropológica em processos criminais do Tribunal de Justiça do Mato Grosso do Sul}

\section{Simone Becker, Olivia Carla Neves de Souza e Jorge Eremites de Oliveira}

Resultado de investigações ligadas aos projetos de pesquisa intitulados "Maiorias que são minorias, invisíveis que (não) são dizíveis: análise etnográfica sobre sujeitos à margem dos discursos dominantes" e "Mapeamento de demandas quanto ao acesso à justiça de indígenas da Grande Dourados/MS", o artigo analisa grosso modo os argumentos que sustentam a negação da feitura de perícia antropológica por parte dos operadores do direito que compõem o Tribunal de Justiça do Mato Grosso do Sul (TJMS), em conflitos criminais. Sublinhamos a prevalência dos princípios do Estatuto do Índio não mais vigentes à luz da Constituição Federal de 1988, bem como a confusão em determinados julgamentos do TJMS entre perícia antropológica e psicológica/psiquiátrica.

PALAVRAS-CHAVE: tribunal de justiça, Mato Grosso do Sul, processos criminais, laudos antropológicos, laudos psicológicos.

The prevalence of an integrationist logic: denials of anthropological assessment on criminal cases of the justice court of Mato Grosso do Sul - Resulting from investigations related to the research projects entitled "Majorities which are minorities, invisible which are (un)speakable: an ethnographic analysis on subjects outside of dominant discourses" and "Mapping of lawsuits regarding the access of Indians of Grande Dourados/MS to justice", the article roughly analyses the arguments that support the rejection of anthropological assessments within criminal cases by law operators of the Mato Grosso do Sul justice court (TJMS). We emphasize the prevalence of the Indian Statute principles, no longer valid according to the Federal Constitution of 1988, as well as the confusion in certain judgments of Mato Grosso do Sul justice court between anthropological and psychological/psychiatric assessments.

KEYWORDS: Mato Grosso do Sul, Justice Court, criminal cases, anthropological assessment, psychological assessment.

BECKER, Simone (simonebecker@ufgd.edu.br) - Faculdade de Direito e Relações Internacionais, Universidade Federal da Grande Dourados, Brasil.

SOUZA, Olivia Carla Neves de (olivia_cndes@hotmail.com) - Faculdade de Direito e Relações Internacionais, Universidade Federal da Grande Dourados, Brasil.

OLIVEIRA, Jorge Eremites de (eremites@hotmail.com) - Instituto de Ciências Humanas, Universidade Federal de Pelotas, Brasil. 
EM AULA MAGNA INTITULADA “O NASCIMENTO DO BRASIL”, PROFERIDA junto ao Programa de Pós-Graduação em Antropologia (PPGAnt) da Universidade Federal da Grande Dourados (UFGD), em Mato Grosso do Sul, Brasil, no mês de abril de 2011 , João Pacheco de Oliveira revisitou o mito fundador do chamado "descobrimento do Brasil". Assim o fez a partir de uma perspectiva antropológica e histórica, cuja discussão central foi objeto de reflexões anteriores (Oliveira 2010). Ao apresentar uma espécie de genealogia sobre o tema, analisou como certas tendências em vigor na historiografia brasileira dificultam a compreensão das diferenças socioculturais inerentes às relações interétnicas e ao reconhecimento de direitos às sociedades indígenas no país. A situação apontada ocorre à medida que a ideologia dominante, de viés colonialista, eurocêntrica e evolucionista, é ratificada na historiografia - ainda que não explicitamente - e passa a ocultar deliberadamente a presença e o protagonismo das sociedades indígenas na história do Brasil. Sua exposição surpreendeu positivamente a dezenas de estudantes e professores de antropologia, direito, geografia, história e áreas afins presentes no evento. Isso porque teve como norte a premissa de contextualizar e colocar em relação os personagens visibilizados em mapas, cartas e pinturas da época colonial, como que dando voz aos indígenas que já estavam no palco do nascimento do Brasil.

Se a história a nós contada nos livros didáticos, ao menos até a década de 1990, desejou que soubéssemos de nosso passado de maneira enviesada, o mesmo estende-se aos discursos legais que fundamenta(ra)m tais omissões e distorções sob a égide do projeto integracionista que sustenta o Estatuto do Índio, a Lei n. ${ }^{\circ} 6001$ de 1973. Nas palavras de Souza Filho (2003: 77): "Ao índio sobrou como direito a possibilidade de integração como indivíduo, como cidadão, ou juridicamente falando, como sujeito individual de direitos. Se ele ganhava direitos individuais, perdia o direito de ser povo".

Este ideal integracionista, ligado à ideia de aculturação e assimilação, consta no artigo 1. ${ }^{\circ}$ da referida lei: "Esta Lei regula a situação jurídica dos índios ou silvícolas e das comunidades indígenas, com o propósito de preservar a sua cultura e integrá-los, progressiva e harmoniosamente, à comunhão nacional" (Brasil 1973: s. p.). Acontece que, com o decorrer dos anos, a tarefa de "preservar uma cultura", tentando ao mesmo tempo integrá-la a outra, revelou-se nada harmônica e, por certo, inviável, uma vez que não se deixa de ser indígena e nem se deixa de ter identidade, a qual é processual e se ressignifica no tempo. Neste sentido, se, por um lado, esse documento trazia algumas garantias aos povos indígenas, por outro lado, explicitava seu intuito, pois a intenção era a de que os índios perdessem a sua identidade cultural para que, em troca, recebessem sua cidadania, eliminando dessa forma o grande problema da diversidade cultural. ${ }^{1}$ 
Graças à intensa mobilização política dos povos indígenas no Brasil durante o processo constituinte, a Carta Magna de 1988 dedicou um capítulo à proteção dos direitos indígenas. A título de contextualização, a Lei Maior representa alguns dos marcos para a sociedade brasileira, tais como: (1) a inauguração do Estado Democrático de Direito, (2) o fim do regime ditatorial e (3) a intensa participação/pressão da sociedade civil na figura das propaladas minorias de acesso a direitos, como os indígenas. Enfim, o paradigma de integração do índio deixa de ser uma previsão legal e em seu lugar é assegurado o direito à diversidade cultural. Isto é o que se interpreta do artigo $231.0^{\circ}$ da referida Carta Política: "São reconhecidos aos índios sua organização social, costumes, línguas, crenças e tradições, e os direitos originários sobre as terras que tradicionalmente ocupam, competindo à União demarcá-las, proteger e fazer respeitar todos os seus bens" (Brasil 1988: s.p.).

Portanto, em face da Constituição de 1988, o artigo $1 .^{\circ}$ do Estatuto do Índio, antes transcrito, perde o seu significado e aplicabilidade. Outro dispositivo do mesmo estatuto cuja acepção é incompatível com o atual texto constitucional é o artigo 4. ${ }^{\circ}$, que dispõe sobre os critérios de classificação dos indígenas em: "isolados", "integrados" e "em vias de integração". A própria expressão "em vias de integração" indica o quanto o teor da redação dessa lei é etnocêntrico, pois prevê uma categoria de índios que, muito embora não estejam integrados, ainda se "converterão" e perceberão que o "caminho" para uma vida melhor é integrando-se à sociedade ocidental. Essa classificação é de uma pretensão ímpar, já que o indígena em "vias de integração" seria aquele que está no meio do "caminho" e por alguns motivos o legislador deduz que seriam grandes as probabilidades de ele se tornar integrado à medida que perderia gradualmente sua indianidade. Tanto é que nem sequer existe a hipótese de os indígenas estarem "em vias de isolamento".

Desde o momento em que a Carta Política liberta-se do intuito integracionista, não há mais razão para diferenciar entre os indígenas tomando como parâmetro a nossa civilização. O que nós temos no país são sociedades indígenas que significam de formas particulares suas maneiras de agir, pensar e sentir, no sentido atribuído por Cardoso de Oliveira (2006: 16) à tolerância como "orientação do diálogo interétnico". Como o conceito de cultura não é estático, em hipótese alguma o fato de terem sofrido modificações deve servir de pretexto para retirar dos indígenas sua identidade cultural (Neto 2002; Laraia 2003).

A mesma Constituição inova quando promove em seu artigo $232 .^{\circ}$ que "os índios, suas comunidades e organizações são partes legítimas para ingressar em juízo em defesa de seus direitos e interesses, intervindo o Ministério Público em todos os atos do processo" (Brasil 1988: s.p.). Até 1988 o indígena era 
considerado "relativamente capaz", devendo ser tutelado. Aqui fazemos outro esclarecimento: os índios nunca foram mentalmente inferiores, mas sim inferiorizados e incompreendidos por pertencerem a contextos produtores de sistemas simbólicos quiçá diversos. Marcelo Beckhausen discute esse apontamento:

"A tutela, na forma como concebida pelo Código Civil e pelo Estatuto do Índio, não existe mais. E incapacidade existiu sim. Os brancos ocidentais nunca tiveram capacidade para entender a diferença cultural existente. [...]. Os nossos Tribunais, infelizmente, são provas documentais de tal incapacidade" (Beckhausen 2009: 2).

Se no âmbito nacional temos na Constituição de 1988 um importante avanço na defesa de direitos de povos indígenas, no campo internacional de direitos humanos temos a Convenção 169 da Organização Internacional do Trabalho (OIT) e a Declaração das Nações Unidas sobre os Direitos dos Povos Indígenas. Em 1989, a OIT, considerando as mudanças verificadas na situação dos povos indígenas e tribais desde 1957, e reconhecendo as aspirações desses povos a assumir o controle de suas próprias instituições e formas de vida, adotou a Convenção 169, a fim de revisar as orientações anteriores. Não mais se verifica a lógica da integração, mas certa tentativa de respeito à integridade - leia-se, cambiante - de valores, práticas e instituições desses povos (Peixoto 2008: 255). Eis um de seus trechos:

"Artigo 9. ${ }^{\circ}$ 1. Na medida em que isso for compatível com o sistema jurídico nacional e com os direitos humanos internacionalmente reconhecidos, deverão ser respeitados os métodos aos quais os povos interessados recorrem tradicionalmente para a repressão dos delitos cometidos pelos seus membros" (Brasil 2004: s.p.).

A supracitada Convenção foi ratificada pelo Brasil através do Decreto n. ${ }^{\circ} 505 \mathrm{l} / 2004$. Por ser um tratado internacional de direitos humanos, é imperioso reconhecer seu status de emenda constitucional, a teor do que prega o §3. ${ }^{\circ}$ do artigo 5. ${ }^{\circ}$ da Constituição Federal (Brasil 1988: s.p.). Esse dispositivo constitucional coloca a Convenção 169 da OIT e a Constituição de 1988 no ápice da hierarquia das leis brasileiras, devendo as normas inferiores segui-las. Destarte, ambas convergem para a revogação tácita de parte do Estatuto do Índio. Entretanto, algumas partes do Estatuto ainda estão em vigor e devem ser interpretadas sob a luz desses dois documentos. Sublinhamos os artigos $56 .^{\circ}$ e $57 .^{\circ}$ como exemplos de dispositivos que não perderam sua validade:

"Art. 56. ${ }^{\circ}$ Parágrafo único. As penas de reclusão e de detenção serão cumpridas, se possível, em regime especial de semiliberdade, no local de 
funcionamento do órgão federal de assistência aos índios mais próximo da habitação do condenado.

Art. 57. ${ }^{\circ}$ Será tolerada a aplicação, pelos grupos tribais, de acordo com as instituições próprias, de sanções penais ou disciplinares contra os seus membros, desde que não revistam caráter cruel ou infamante, proibida em qualquer caso a pena de morte" (Brasil 1973: s.p.).

A Declaração das Nações Unidas sobre os Direitos dos Povos Indígenas (Nações Unidas 2011), embora não possua força vinculativa, é outro documento importante por ser uma recomendação da Organização das Nações Unidas (ONU) para todos os países membros da entidade. Apesar de estarem vigorando, estas determinações geralmente são negadas em processos criminais nos quais os réus são indígenas - sobretudo em se tratando de crimes hediondos -, e estes frequentemente são submetidos às sanções previstas na legislação penal brasileira e as cumprem em estabelecimentos penais comuns. Uma boa demonstração disso é o estado brasileiro de Mato Grosso do Sul, localizado na região Centro-Oeste, onde se verifica o maior número de índios encarcerados no país. De acordo com notícia do site Consultor Jurídico (Conjur 2009), em abril de 2009 os presídios abrigavam 148 indígenas, segundo levantamento da Agência Estadual de Administração do Sistema Penitenciário (Agepen). Aliada a esta ilustração, veremos abaixo a desconsideração da aplicabilidade do Estatuto do Índio no que diz respeito a estes dispositivos ainda vigentes.

\section{PLURALISMO JURÍDICO: A IMPORTÂNCIA DOS LAUDOS ANTROPOLÓGICOS APÓS A CONSTITUIÇÃO DE 1988}

Pode-se definir como pluralismo jurídico a coexistência de normas de outras sociedades paralelamente ao ordenamento jurídico nacional. O pluralismo jurídico não é um fenômeno novo. Ele surge com a entrada dos europeus no continente americano. Entretanto, como bem explica Wolkmer (2008), os parâmetros constitutivos da legalidade colonial brasileira negaram radicalmente o pluralismo jurídico nativo (indígena e africano), reproduzindo um arcabouço normativo legitimado pela elite a serviço dos interesses da metrópole.

A Constituição de 1988 inaugura, pois, uma era de respeito ao pluralismo jurídico. No tocante aos indígenas, posteriormente, surgem normas reconhecendo os sistemas jurídicos dessas sociedades para além do modelo imposto pelo Direito estatal. O exercício de reconhecer as normas jurídicas indígenas, consequentemente, acarreta na aplicação relativizada das normas estatais a tais sujeitos. Isso porque há a possibilidade de a norma estatal entrar em choque com as normas internas de um povo indígena, ocasião em que deve ser feito primeiramente um juízo sobre a legitimidade e a exigibilidade da norma da sociedade envolvente perante o membro de determinada etnia. 
Nesse sentido, Marco Antonio Barbosa sintetiza de que forma a análise da legitimidade deve ser feita:

"A legitimidade das normas jurídicas do Direito estatal brasileiro, para as sociedades indígenas, está condicionada à sua capacidade de garantir o que estas sociedades entendem como seus direitos. Isto quer dizer: para a sociedade indígena e seus indivíduos, a lei do Estado Brasileiro só é legítima quando prevê e aplica convenientemente aquilo que a sociedade indígena concebe e admite como Direito. Neste caso, embora unilateral por não ter contado com a participação no seu processo político de elaboração, dos afetados, a lei provavelmente passará a ser aceita pelas sociedades indígenas e seus indivíduos. Fora dessa hipótese, ela será ilegítima pela falta de participação, pelo menos teórica, dos sujeitos de direito na sua elaboração e execução. Quanto à legitimidade das normas jurídicas das sociedades indígenas, como são, via de regra, restritas ao seu próprio espaço territorial, político e social, elas serão sempre legítimas para os afetados, por terem sido criadas e aplicadas por eles próprios. Tal legitimidade só será questionada quando sua aplicação incidir sobre sujeitos oriundos de outras sociedades, pelos mesmos motivos óbvios" (Barbosa 2001: 20).

Assim, o presente artigo foca-se no Direito Penal, por acreditarmos que, neste campo, os reflexos da diversidade cultural saltam aos olhos, como bem avaliam Erika Magami Yamada e Juliana Belloque:

"No âmbito do Direito Penal, os conflitos de diferentes ordens jurídicas e costumes se apresentam com maior nitidez do que nos outros ramos do Direito. Isso se deve ao fato de que o Direito Penal encontra seu fundamento num conjunto de valorações sociais - e cosmovisão etnocêntrica - a serem protegidas. [...] Assim, o não reconhecimento das formas distintas de organização social, dos costumes e tradições, dos valores e da moral indígenas (tal como prevê o artigo $231 .{ }^{\circ}$ da Constituição Federal brasileira) no processo criminal compromete a garantia do tratamento justo a ser dispensado aos índios (agressores ou agredidos), seus familiares e por vezes até a comunidade" (Yamada e Belloque 2010: 125).

Portanto, conflitos criminais exigem uma atenção redobrada, devendo o magistrado atentar-se para a existência da diversidade de valores, toda vez que membros de sociedades tradicionais figurarem nos processos. Sugerimos que esse exercício de relativização torna ainda mais complexa a tarefa de julgar, não só devido à deficiência de formação antropológica nas graduações dos cursos de Direito do Brasil, como também ao fato de que certos valores indígenas muitas vezes só se tornam compreendidos por aqueles que tenham estudado 
e convivido com determinada etnia por um período razoável de tempo. Justamente por isso, esta análise de "imputabilidade" deve ser obtida com auxílio de uma perícia antropológica, para o fim de dar atenção à particularidade de cada caso, ou seja, de cada sujeito indígena e de cada etnia. Em suma, o simples fato de o indivíduo ser indígena não o exime de responder penalmente pelos seus atos perante a Justiça brasileira. Mas o ser indígena é o que basta para propiciar-lhe um laudo antropológico, eis que a garantia de um julgamento em conformidade com a sua cultura é uma exigência do sistema constitucional (Pontes 2010: 221).

Antes de avançarmos sobre as contribuições antropológicas no âmbito do judiciário, é importante reforçar ao leitor que, para além de quaisquer justificativas produzidas pela antropologia, há aquelas jurídicas/legais voltadas à necessidade de perícias antropológicas em processos criminais. Não se trata de empatia (per se) pelas causas indígenas, pois no Brasil a discussão já superou essa fase com a Constituição de 1988. Agora, trata-se de efetivar a garantia disposta no artigo 231. ${ }^{\circ}$ da citada Carta Política. Sob este enfoque, o tratamento penal que o indígena receberá por cometer um ilícito criminal variará conforme a conclusão do laudo antropológico, o qual, inclusive, poderá servir de respaldo para a condenação do réu, haja vista que o juiz brasileiro apresenta a liberalidade legal de decidir acatando ou não o parecer de qualquer expert.

Sugerimos até então que alguns crimes previstos no Código Penal brasileiro não são considerados atos reprováveis no contexto de certas culturas indígenas. Para ilustrar o que até aqui foi dito, trazemos à tona certos casos a partir dos quais o laudo antropológico foi o elemento norteador do processo, revelando particularidades até então desconhecidas, as quais alteraram o rumo da decisão judicial. O primeiro deles ocorreu no município paranaense de São Jerônimo da Serra, mais precisamente no distrito de São João dos Pinhais. Naquela localidade, no dia 16 de novembro de 1997, o indígena Reginaldo Salles Batarse, kaingang, ${ }^{2}$ cacique da reserva indígena de Barão de Antonina, e ainda o líder indígena João Teixeira foram acusados de matar a tiros Adenilson da Silva Cruz, também conhecido na região por "Nego Saruê". O crime de homicídio chegou ao conhecimento do Judiciário Federal de Londrina, estado do Paraná, onde iniciou o processo penal sob a identificação numérica 2001.70.01.005471-1. $\mathrm{Na}$ ocasião, o procurador da República, João Akira Omoto, solicitou a perícia antropológica, a qual foi prontamente deferida pelo juiz federal Robson Carlos de Oliveira. E foi o laudo antropológico produzido em 2003 pela antropóloga Elaine Amorim Carreira, do Ministério Público Federal (MPF), que, trazendo à luz diversos detalhes, mudou o rumo do processo, resultando no seu arquivamento. Segue um fragmento da conclusão de seu estudo: 
“O homicídio em análise ocorreu em circunstâncias acentuadamente marcadas pelo conflito fundiário. O distrito de São João do Pinhal figurava como espaço sob o domínio de Nego Saruê e demais invasores, onde consequentemente, os índios de Barão de Antonina sentiam intimidados e inseguros. Praticamente não o frequentavam naquele momento. Era na verdade, território inimigo. Quando o cacique Reginaldo e o líder João Teixeira tiveram de ir, foram armados, mas não com espírito de provocação e sim de defesa. Precisavam resolver um problema concreto de manutenção das estradas de acesso à aldeia e não tinham segurança. De fato, foram agredidos; e a agressão partiu dos invasores. Após o ocorrido (homicídio), os invasores se encolheram e o movimento se extinguiu. Ou seja Nego Saruê era o elemento aglutinador fundamental das invasões e morreu quando liderava um ataque contra o cacique da aldeia. [...]

Ante o exposto, concluímos que o homicídio ocorreu por causa dos conflitos fundiários interétnicos, foi provocado pelos invasores brancos e os acusados agiram em situação de defesa e não ataque" (Amorim 2010: 165).

A perita realizou, durante dez dias, um estudo na aldeia de Barão de Antonina, onde constatou que a figura de Nego Saruê causava muito temor entre os indígenas, já tendo incendiado casas da reserva, ameaçado e tentado matar várias lideranças indígenas (Rocha 2008). Importante salientar que tais informações só vieram à tona através do laudo antropológico e que o processo foi arquivado por concluir que o crime havia sido praticado em legítima defesa, não só do cacique Reginaldo que havia sido agredido por Nego Saruê, mas também em legítima defesa da própria etnia kaingang de Barão de Antonina. ${ }^{3}$

Sem o laudo acima, provavelmente o cacique Reginaldo seria considerado mais um índio que fala fluentemente o português e que sabia que "matar alguém" é crime. Todavia, para a comunidade de Reginaldo sua conduta era perfeitamente compreensível, diante do contexto enfrentado e que só veio a lume com o estudo antropológico.

Outro caso brasileiro emblemático e histórico é o de Basílio Alves Salomão, membro da etnia macuxi da comunidade indígena do Maturuca, que matou Valdenísio Silva, indígena da mesma etnia, em 1986. Nessa época, Basílio era tuxaua de sua comunidade, ${ }^{4}$ e por essa razão sofreu a condenação dos índios macuxi, que se reuniram aplicando-lhe a seguinte pena: cavar a cova de sua vítima e submeter-se ao desterro, longe da comunidade e de sua família.

3 A legítima defesa é uma categoria (êmica) legal a partir da qual o crime de homicídio não é passível de condenação, pois o sujeito supostamente homicida agiu se defendendo e defendendo sua própria vida.

4 Em algumas etnias, tuxaua é o chefe da aldeia, sujeito com autoridade para resolver conflitos, convocar reuniões ou festas e orientar variadas atividades. 
A despeito da condenação imposta pela sociedade macuxi, houve a instauração posterior do processo criminal identificado sob o n. ${ }^{\circ}$ 92.0001334-1, que tramitou na 2. ${ }^{\text {a }}$ Vara da Justiça Federal de Roraima. Em 1995, o MPF requereu a realização de perícia antropológica, a qual foi realizada pela antropóloga Alessandra Albert. O caso só foi a julgamento no Tribunal do Júri em 2000. Estella Libardi de Souza é quem melhor comenta os aspectos que foram analisados pela antropóloga nessa perícia:

“Quanto ao 'grau de imputabilidade', o laudo argumentou que não se pode basear num suposto 'grau de aculturação', por este revelar o etnocentrismo da sociedade nacional, que toma a si própria como parâmetro de comparação. Por fim, o laudo destacou a vigência de um sistema penal aplicado pela comunidade, que, como demonstrou o caso de Basílio, consiste no julgamento por um conselho de Tuxauas, que analisa os fatos e ouve o réu, aplicando pena de acordo com as tradições e com o acordo da família do ofendido e do restante da comunidade, devendo o cumprimento da pena ser fiscalizado pelo Tuxaua. No caso de Basílio o laudo informa que este ainda se encontrava cumprindo a pena - de início, mais rigorosa, depois, mais flexível - e que contava, no momento de elaboração do laudo (junho de 1995), com quase 10 anos" (Souza 2008: 5-6).

Uma particularidade interessante do caso Basílio é que o juiz considerou que ele "era um tanto quanto aculturado e integrado à cultura brasileira predominante" e, ainda, que não era "alienado da vida civilizada". Contudo, ao ser levado ao júri popular, Basílio foi absolvido por unanimidade pelos jurados, os quais reconheceram que o fato de ele já ter sido punido em sua comunidade era suficiente para isentá-lo de pena perante a Justiça brasileira.

Os dois casos antes suscitados foram eleitos porque são casos que corriqueiramente chegam até o judiciário, pois envolvem indígenas considerados "em vias de integração" e "integrados" à sociedade brasileira e que conforme reiteram julgamentos das cortes superiores - o Supremo Tribunal Federal (STF) e o Superior Tribunal de Justiça (STJ) - dispensariam a perícia. Entretanto, ainda assim, o laudo antropológico foi realizado, tendo o fundamental papel de revelar particularidades até então desconhecidas pelo órgão julgador, as quais tiveram o condão de modificar o teor da decisão, enaltecendo o que se entende como "pluralismo jurídico".

\section{LAUDOS ANTROPOLÓGICOS E A VISÃO DO CONFLITO SEM AS LENTES DO ETNOCENTRISMO}

Ao falarmos de "laudos antropológicos", algumas contextualizações devem ser feitas, muito embora nosso objetivo neste artigo não seja o de retraçar 
quaisquer retrospectos históricos deste particular "fazer antropologia". Porém, como se trata de particularidade que singulariza a antropologia brasileira (Leite 2002: 31), certas pontuações são providenciais.

Em solos brasileiros, a entrada dos laudos antropológicos no contexto do judiciário, e, então, do antropólogo neste palco vincula-se à demanda de direitos por partes de grupos historicamente excluídos deste e por este discurso dominante. A respeito desta questão, a Constituição Federal de 1988 é a referência para os estudos clássicos envolvendo laudos antropológicos no país, mais especificamente na temática da delimitação de territórios indígenas e quilombolas. Nas palavras da antropóloga Ilka Boaventura Leite:

"Entre 1994 e 1996, durante a gestão de João Pacheco de Oliveira à frente da $\mathrm{ABA}$, a perícia, até então restrita quase que exclusivamente às terras indígenas, passou a incluir as terras e o patrimônio das comunidades remanescentes de quilombos, bem como a dimensionar o impacto sofrido por tais grupos frente a questões sócio-ambientais e a grandes projetos de desenvolvimento.

Na década de 1990 ganha corpo a noção de um Brasil pluriétnico e pluricultural, sendo registradas intensas discussões antropológicas sobre cidadania, direitos humanos, justiça e diversidade cultural. A ABA teve atuação decisiva nessa fase, especialmente no que se refere ao diálogo com operadores do Direito, legisladores, representantes de indígenas e de quilombolas e com as procuradorias federais e estaduais. Este contexto é crucial para se avaliar a importância dos laudos periciais e do debate instaurado no seio da comunidade científica sobre o papel da perícia antropológica" (Leite 2005: 20).

Assim, se no Brasil a profissionalização do antropólogo ainda não existe como há em relação aos sociólogos, como bem remarca Leite (2005), a atuação da Associação Brasileira de Antropologia (ABA) e os intensos diálogos estabelecidos com os profissionais do direito fazem com que a antropologia feita nos laudos angarie destaque. Mais especificamente, isto acontece porque o MPF, instituição fundamental na organização judiciária após a vigência da Carta Constitucional de 1988, ao atuar na defesa de direitos coletivos das antes propaladas minorias (Arantes 1999), desde a década de 1990 incorpora em seu quadro funcional os antropólogos (Amorim, Alves e Schettino 2010). Paralelamente, destacamos que em 2001 o documento "Carta de Ponta das Canas", aprovado em reunião realizada pela ABA em Florianópolis, Santa Catarina, traz consigo as diretrizes voltadas ao trabalho do antropólogo em meio aos laudos (Leite 2002).

Quanto ao estado do Mato Grosso do Sul, os antropólogos Levi Marques Pereira e Jorge Eremites de Oliveira (Oliveira e Pereira 2009, 2012), em laudos publicados pioneiramente, destacam que é "desde a década de 1990 que a 
Justiça Federal tem determinado a realização de laudos periciais de natureza antropológica, arqueológica e histórica sobre terras reivindicadas por comunidades indígenas no estado do Mato Grosso do Sul" (Oliveira e Pereira 2009: 15).

Nos últimos anos, as demandas no campo do judiciário se voltam também ao questionamento por parte dos grupos étnicos quanto à necessidade da feitura de perícias antropológicas em disputas criminais em que os sujeitos indígenas, por exemplo, figuram como réus. Novamente, retomamos as contribuições de Leite (2005: 24), quando menciona que "uma variante cada vez mais requisitada desses estudos é a do processo penal - em que se verifica a imputabilidade criminal de indivíduos pertencentes a grupos etnicamente diferenciados ou a de quem atente contra o direito coletivo de tais grupos".

Retenhamos os dizeres de Ilka Boaventura Leite, à medida que a nossa análise volta-se à questão da "imputabilidade criminal" ou da possibilidade que o discurso jurídico crê que o sujeito detém para suportar a punição decorrente de uma condenação criminal, quando o acusado de pretensa prática criminosa é um indígena. Como atrás também destacamos, para que haja a perícia antropológica, basta que o sujeito assim se identifique e que seu pertencimento seja reconhecido pela comunidade indígena. Aliás, critérios decorrentes da "autodeterminação", constante na Convenção 169 da OIT, são sustentados pela teoria antropológica social que descola a "identidade cultural" do caráter biológico. Mas, mais do que isto, torna-se indispensável nova remissão a um dos principais documentos que norteiam a feitura de perícias antropológicas em solos brasileiros, a mencionada "Carta de Ponta das Canas", produzida por antropólogos no diálogo com operadores do direito, a fim de conceder diretrizes sobre este peculiar "fazer antropológico". Neste documento, em especial no item destinado ao "controle da qualidade dos trabalhos realizados", algumas considerações são feitas (in)diretamente sobre a pertinência dos laudos antropológicos, aplicáveis, a nosso ver, àqueles envolvendo indígenas em conflitos criminais, cuja autodeterminação é o elemento indispensável para o deferimento da perícia antropológica. Passemos às considerações da "Carta de Ponta das Canas":

“- O processo de reconhecimento de grupos étnicos indígenas [...] para fins de aplicação de direitos constitucionais tem produzido, por parte dos órgãos do Estado, a demanda por peças técnicas antropológicas de identificação étnica e tais demandas têm sido geradas a partir de contextos conflitivos;

- Nestes contextos, a reivindicação de uma identidade étnica e social tem sido associada a uma suspeita de manipulação instrumental, pelos atores sociais, de categorias identitárias contempladas por direitos constitucionais;

- A experiência tem demonstrado que as manifestações de autoatribuição étnica não têm assegurado, por si só, o reconhecimento de direitos diferenciados por parte do Estado Brasileiro" (Nuer 2001: 10). 
Voltando ao nosso objeto de pesquisa e retidas as pontuações antes feitas, passemos, então, às diferentes matizes que, a nosso ver, por vezes tanto mancham e apagam a interdisciplinaridade intrínseca ao métier jurídico quando em cena estão os laudos antropológicos em conflitos criminais envolvendo indígenas.

\section{AS TESSITURAS DE APELAÇÕES CRIMINAIS NO TJMS ENVOLVENDO LAUDOS ANTROPOLÓGICOS INDÍGENAS}

A feitura de etnografia é realizada, em regra, nas aldeias (Geertz 1978), porém, estas aldeias podem ser "arquivos" no sentido restrito aos "documentos", e não apenas quando a abordagem antropológica dialoga com a história. Neste sentido, Leite (2002: 35), ao remarcar as particularidades do "fazer antropologia" nos laudos, refere-se ao "passado etnográfico" como o resultado advindo da "memória, do pesquisador com os documentos e com os seus entrevistados". É o que Sérgio Carrara denomina de "aldeias arquivos", face ao fato de sua concretude se reduzir a "um amontoado de papéis, fichas, cópias, anotações e resumos feitos a partir de documentos que, pacientemente ou não, vai-se coligindo em bibliotecas ou empoeirados arquivos" (Carrara 1998: 53-54). Aqui, nossas aldeias são os julgamentos judiciais categorizados também como "acórdãos" pelo discurso nativo êmico e se restringem ao Tribunal de Justiça do Mato Grosso do Sul, por certas particularidades desta região brasileira.

Restringimos nossa busca ao website do TJMS. ${ }^{5}$ Assim o fizemos sob a justificativa - talvez não tão óbvia aos olhos daqueles que não moram no Brasil e em Mato Grosso do Sul - de que no município de Dourados e cidades circundantes vivemos em constante cozimento dentro de uma grande "panela de pressão" ora porque neste está a segunda maior população indígena do país, com cerca de 70.000 pessoas, ora porque grande parte desta população foi territorializada em diminutas reservas indígenas (Lenharo 1986) ao longo do século XX, e sob este processo quiçá sobreviva reificando as noções de etnocídio e genocídio.

Sob estas perspectivas, ao longo dos anos de 2010 e início de 2011 , nas "aldeias arquivos" (ou sítios) do TJMS, utilizamos como palavra-chave no buscador de "jurisprudências" a expressão "laudo antropológico". ${ }^{6} \mathrm{O}$ objetivo

5 Indicamos o sítio virtual de nossas imersões documentais, www.tjms.jus.br, para que o leitor possa conhecer este espaço de produção de discursos dominantes (cf. Bourdieu 1998).

6 A categoria nativa das jurisprudências norteia, em grande medida, a lógica jurídica no Brasil, diferentemente do que ocorre em outros países. Elas se caracterizam como julgamentos feitos por cortes superiores aos juízes/magistrados que primeiramente decidiram os respetivos conflitos judiciais, e a sua singularidade consiste na reiteração destas decisões acerca de uma mesma temática. Neste sentido, teremos sobre a "imputabilidade criminal" de indígenas, por exemplo, aqueles blocos de julgamentos que são favoráveis e os que são contra. Em meio a esta dualidade haverá as diferentes nuanças de argumentos que sustentam o deferimento e o indeferimento da feitura das perícias e consequentes laudos antropológicos. 
inicial da pesquisa voltava-se à análise dos argumentos que negavam ou determinavam a realização de perícias antropológicas e seus respectivos laudos em conflitos de ordem criminal. Frente à possível mudança de acórdãos inseridos ou retirados do website do TJMS, aos sete dias do mês de junho de 2011 refizemos o caminho outrora percorrido, e ao digitarmos a palavra-chave "laudo antropológico" chegamos a 23 acórdãos. Dois deles referiram-se à área cível e os 21 restantes à área criminal, foco esse de nossos interesses analíticos na mudança de nossos percursos de pesquisa. Em síntese, se inicialmente desejávamos nos centrar nos argumentos que deferiam e que negavam as perícias antropológicas, em ato contínuo, frente à maioria esmagadora de julgamentos que refutavam os laudos, nos focamos em suas compreensões analíticas.

Quanto aos processos criminais, independentemente da negação dos laudos antropológicos, todos eles se referem a contestações a decisões anteriores produzidas por magistrados no e para o discurso jurídico na forma de "recursos". No que diz respeito à classificação do crime imputado ao réu indígena, seis dos processos criminais são de estupro, um de abandono de incapaz e maus tratos, dez de homicídios, um de tentativa de homicídio, um de tráfico de entorpecentes e dois de roubo. Estes dados são aqui apenas lançados ao leitor, mas futuramente serão objeto de aprofundamento e cruzamento com os demais vetores que se tornam relevantes para o entendimento da prevalência dos princípios integracionistas do Estatuto do Índio, que se mantém totalmente em vigor para muitos magistrados. E mais: com base nos subsídios teóricos da criminologia liberal (Zaffaroni 2001), das noções de dispositivo atreladas às de arqueologia do saber, genealogia do poder, da produção de verdades sobre os sujeitos para Michel Foucault (1983, 2003), e finalmente, de "desvio" (Becker 2008; Velho 1985), poderemos analisar as razões que tornam determinados crimes (e não outros) elementos de captura dos sujeitos assujeitados indígenas pelo sistema prisional.

Voltando aos 21 acórdãos criminais selecionados no website do TJMS, há que se destacar que o principal argumento levantado para a sustentação do pedido de perícia antropológica por parte dos representantes dos indígenas indiciados centra-se na nulidade de todo o andamento judicial do conflito por "cerceamento de defesa". Ou seja, com sucintos esclarecimentos quanto ao que revestiria esta categoria nativa do "cerceamento de defesa", o que se repete ao longo dos 21 julgamentos centrados em litígios penais é a impossibilidade de construir discursivamente a defesa do sujeito indígena se a perícia antropológica não for realizada, cujas nuanças detalharemos no próximo item.

Em meio a estes 21 processos criminais, em apenas três deles houve a sinalização para o deferimento da feitura da perícia antropológica. Como este não foi o foco do presente trabalho, chegamos assim aos 18 julgamentos que negaram a realização de perícia antropológica. As bússolas que nortearam nosso olhar para a leitura das recorrências de argumentos que indeferiram as perícias 
foram as metodologias genealógica e arqueológica de Michel Foucault. Por que esta lente e não outra ancorada nos demais métodos de análise discursiva? Nossa resposta é objetiva quanto a esta escolha, uma vez que a categoria analítica escolhida a priori - no caso "laudo antropológico" - por si só reflete os exercícios de poderes que se (re)fazem perceptíveis no contexto do judiciário que não apenas tem o condão de produzir sujeitos (Butler 2004), mas também o de (re)atualizar as disputas entre saberes (re)conhecidos como científicos (Foucault 2003). Assim, é a partir dos estabelecidos saberes do direito e da medicina/psiquiatria e seus exercícios de poderes que, em meio à arena do judiciário, eles próprios se revigoram e passam (ou não) a dar vigor ao estabelecimento de outras áreas científicas. A antropologia aqui está em meio às tessituras dos argumentos produzidos nos 18 julgamentos que negaram a entrada do antropólogo neste lócus. Passemos a eles.

\section{ARGUMENTOS QUE NEGAM A FEITURA DE PERÍCIA ANTROPOLÓGICA: QUEM DIAGNOSTICA O "SINTOMA" E FAZ A "PERÍCIA BIOPSICOLÓGICA"}

Na sequência, então, nos dedicaremos à análise dos casos por nós considerados emblemáticos, dada a recorrência de três argumentos para a negação da feitura dos laudos, a saber: imputabilidade e inimputabilidade indígena; confusão entre perícia psiquiátrica e antropológica; remissão à taxionomia identitária dos indígenas como integrados, em vias de integração ou isolados.

Vanderlei Mendes é o réu da contestação (ou do "recurso em sentido estrito") à primeira decisão produzida em seu processo que determinou que ele respondesse por homicídio, sentando no banco dos réus do tribunal do júri. ${ }^{7} \mathrm{O}$ movimento de seu advogado foi justamente o de evitar que ele fosse "pronunciado" ou respondesse por homicídio, frente a duas argumentações centrais: "cerceamento de defesa" pelo indeferimento da perícia antropológica e "legítima defesa" por ter atirado contra outra pessoa para se defender do ataque. A identidade de indígena aparece no documento analisado (recurso sob o n. ${ }^{\circ}$ 2007.031540-7/0000-00; ver TJMS 2007) imbricada à argumentação de cerceamento de defesa, como forma de repúdio à refutação da perícia por parte do primeiro juiz que julgou o conflito. Se, conforme acima enfatizamos, o cerceamento de defesa é uma categoria êmica voltada à argumentação sobre algo que obstaculiza a produção discursiva de quem defende alguém no judiciário, no caso de Vanderlei Mendes sublinhamos que o laudo antropológico é atrelado ao cerceamento de defesa para que o advogado do indígena, Juscelino Joaquim

7 Apenas são levados a júri popular os crimes dolosos (com intencionalidade) praticados contra a vida. Nestes são os pares do réu, integrantes da comunidade, que o julgam, decidindo se é caso de condenação ou não. A propósito, no caso de réus indígenas, deveria haver membros da sua etnia entre os jurados eleitos, já que a ideia é que o indivíduo seja julgado por seus pares frente à lei brasileira. 
Machado, possa argumentar o quão "silvícola" Vanderlei é. Percebam que, neste caso, a lógica que movimenta o pedido da feitura de perícia antropológica realimenta a lógica da própria decisão que a denega, à medida que ambas se ampararam na mesma moeda integracionista veiculada pelo Estatuto do Índio. Mais precisamente, o defensor insiste que Vanderlei Mendes está em "vias de integração" à sociedade envolvente, ao passo que o magistrado e o desembargador "relator" do TJMS afirmam que ele está integrado à sociedade "branca". ${ }^{8}$

Para o desembargador, João Batista da Costa Marques, a dispensa da perícia antropológica se justifica porque neste caso há evidências convincentes de integração postas nos documentos que compõem o que se denomina de "autos de um processo", não carecendo de um expert denominado de antropólogo para identificá-los. O relator sustenta sua tese afirmando ainda que "é farta a jurisprudência no sentido de que o laudo de exame antropológico não é obrigatório na análise da integração do índio à sociedade. Só se exige essa providência quando os indícios demonstram que o índio é silvícola carente de integração com o homem branco" (TJMS 2007: s. p.). ${ }^{9}$ Se a decisão do juiz do TJMS evoca a obsoleta classificação constante no Estatuto do Índio em seu artigo $4 .^{\circ}$ e traz para si, com o artifício do "livre convencimento", a dispensa da perícia antropológica, ela assim o faz tomando essa última enquanto sinônimo de "perícia biopsicológica". ${ }^{10}$

Em síntese, o desembargador João Batista da Costa Marques articula a tese de que Vanderlei Mendes já se integrou aos "costumes da Nação civilizada" ou do "homem branco", com base em seu livre convencimento. Notem que o "grau de discernimento do índio" quanto à "sua integral adaptação ao nosso meio social" (TJMS 2007: s.p.) é avaliado pelo juiz, que o faz pinçando sinais da civilidade do indígena ao longo dos documentos transcritos e anexados aos autos do processo. Isso é feito colocando a expertise jurídica à frente do discurso médico/psiquiátrico, dispensando a perícia biopsicológica (Foucault 2003), confundida como sinônima de perícia antropológica. Quais são estes sinais de integração do indígena em questão, apontados pelo julgador no conflito de Vanderlei Mendes? Inicialmente, ele afirma que a negação da perícia antropológica se dá pelo fato de que no processo o acusado jogava vôlei ao invés de praticar danças tribais relativas à sua comunidade. Acompanhemos:

8 Como são três desembargadores em cada julgamento, cabe ao "relator" ler todo o processo em questão, com consequente produção de seu "voto/decisão", que, no dia do julgamento, será objeto de concordância ou discordância por parte dos outros. Quando se trata de conflitos sem importância, atribuída em regra pela mídia, os demais julgadores seguem o voto do relator.

9 O artigo 184. ${ }^{\circ}$ do atual Código de Processo Penal, de 1941, determina que "salvo no caso de exame de corpo e delito, o juiz ou a autoridade policial negará a perícia requerida pelas partes, quando não for necessária ao esclarecimento da verdade" (Brasil 1941: s. p.).

10 "Livre convencimento" é o princípio que norteia os poderes dos magistrados, inclusive para fundamentar sua decisão dispensando as perícias em geral, não apenas as realizadas por antropólogos. 
"O próprio interrogatório do recorrente, f. 149/150, demonstra a lucidez quanto ao seu conceito sobre os costumes do homem branco, $[\ldots]$ em certo trecho diz: 'Que o interrogando estava jogando vôlei com os amigos...' Assim, evidenciado que o recorrente ao invés de praticar as danças naturais da tribo ou competições compatíveis com sua origem, preferia jogar vôlei, o que demonstra o seu grau de desenvolvimento e integração ao mundo do homem branco" (TJMS 2007: s.p., itálicos e destaques no original).

Finalizando, o desembargador remete-se aos fundamentos do magistrado que primeiro julgou a causa, explicando a serventia da perícia antropológica confundida com a biopsicológica. Visualizemos:

“[...] o magistrado justificou as razões para não permitir que fosse realizada essa perícia. [...], f. 280: '... há de ressaltar que entendo desnecessária a realização de perícia bio-psicológica no acusado, eis que o mesmo, apesar de ser indio, é integrado a sociedade, pois é alfabetizado, possui aptidão para o trabalho e apresentou, por ocasião de seu interrogatório, capacidade de entender o caráter ilícito do fato e de determinar-se de acordo com esse entendimento"' (TJMS 2007: s.p., itálicos no original).

Os sinais de civilidade para estes julgadores correspondem àqueles da integração sob um conjunto de características que tornam estática a dinâmica expressão constitucional "diversidade cultural", e se reduzem à somatória de jogar vôlei, ser alfabetizado na língua portuguesa - a despeito do uso da língua materna por força da Constituição Federal -, ter (sem intérprete) articulado vis-à-vis com o magistrado singular, na audiência de interrogatório, seu entendimento de que praticara o ilícito definido no Código Penal brasileiro, e possuir aptidão para o trabalho, reiterando o vínculo de Vanderlei Mendes ao silvícola evocado pelo seu próprio defensor.

Duas pontuações são essenciais para compreender o assunto, a primeira quanto à aparente confusão entre perícia antropológica e biopsicológica, a segunda quanto à serventia da perícia antropológica nos moldes em que a antropologia social brasileira a concebe no contexto do judiciário.

A primeira delas é quanto à aparente confusão entre perícia antropológica e biopsicológica. Usamos o termo "aparente" porque na clássica obra de Lilia M. Schwarcz (1993), bem como em todos os principais referenciais teóricos alocados na antropologia que sustentam a criminologia crítica (Baratta 2002, dentre outros), as influências da antropologia criminal de Césare Lombroso sob as investidas evolucionistas sociais com viés determinista biológico (racistas) encontra(ra)m terreno fértil no Brasil. Neste sentido, não há uma confusão se considerarmos que foi, e para alguns continua sendo, a antropologia criminal lombrosiana uma das fortes influências dos bacharelados em direito 
em solos brasileiros (Schwarcz 1993; Alvarez 2002). Torna-se uma confusão, na medida em que os referenciais que balizam as atuais perícias não bebem em contribuições evolucionistas sociais, mas na antropologia social moderna com suas mais distintas influências, sobretudo estadunidenses, inglesas e francesas.

A segunda e essencial pontuação diz respeito à pormenorização da serventia do antropólogo em perícias criminais. Propositadamente nos deslocamos para as fundamentações de Roberto Lemos dos Santos Filho (2011), juiz federal da cidade de Bauru, estado de São Paulo, que no processo n. ${ }^{\circ}$ 0005381-95.2008. 403.6108 negou o recebimento de uma denúncia, ou seja, do pedido feito pelo promotor de justiça para transformar a investigação policial em processo judicial, devido à ausência de laudo antropológico. Fundamentalmente, este juiz nos adverte que, no conflito por ele analisado, iniciar a ação penal de cárcere privado contra lideranças indígenas por manutenção de funcionários da Funai como reféns é, em sua visão, ignorar que tais atos a princípio se configuram como legítimos frente à necessidade de os índios serem ouvidos. E mais: além da necessidade de os indígenas terem voz e de serem ouvidos, Roberto Lemos acredita ser necessário que estes sujeitos recebam atenção quanto às suas reivindicações, "o que de rotina não é verificado tanto com relação aos índios de Avaí-SP, quanto com relação aos indígenas de todo o Brasil" (Santos Filho 201 l: s.p.), face ainda ao processo de não descolonização por parte dos discursos de autoridade. Para o mencionado juiz federal, a compreensão por parte dos indígenas de que suas atitudes eram ou não lícitas só poderá ser aferida com a perícia antropológica. Trata-se, sublinha o mesmo, de compreender se para aqueles indígenas da reserva de Araribá, no estado de São Paulo, a retenção dos funcionários da Funai é um ato ilícito segundo seus "costumes", que, de maneira a dar dinamismo à diversidade cultural, são tomados como sistemas simbólicos. Isto quer dizer que deveria ser analisado se é ilícito ou não no e para o contexto social onde as lideranças indígenas de Araribá vivem, mesmo que haja uma legislação nacional dominante que pretenda homogeneizar o que é crime para a sociedade brasileira como um todo. Admitir esta homogeneidade é ignorar o artigo $231 .^{\circ}$ da Constituição Federal e, além disto, ignorar toda a concepção mais ampliada do que em antropologia do direito se entende a respeito do antes esmiuçado "pluralismo jurídico". A priori isso é algo que pode ser medido por qualquer leigo, bastando que para tanto tenha contato com indígenas, mas que não o é, haja vista o conjunto de particularidades demandadas pelo expert antropólogo em meio a esta arena jurídica (ver "Carta de Ponta das Canas", Nuer 2001).

Neste sentido, o juiz menciona Luiz Fernando Villares para desconsiderar a apropriação por parte dos indígenas de hábitos da sociedade "branca" como indícios de que os mesmos são integrados:

"Considerar por aspectos externos de fácil apreensão que o índio é inteiramente capaz de entender o caráter ilícito dos fatos ou de determinar-se 
de acordo com esse entendimento faz parte da arrogância do direito, e do julgador, que reputa ter ciência bastante para julgar sem auxílio de técnicos. Ver aspectos formais como o grau de escolaridade, o entendimento do idioma oficial, título de eleitor etc..., é privilegiar a verdade formal em detrimento do mundo real. O índio pode mostrar-se externamente apto a todos os atos da vida, mas, internamente, sem o entendimento perfeito do caráter ilícito da conduta, ou mesmo, entendendo a ilicitude, não podendo agir diferente por sua cultura assim exigir" (Santos Filho 2011: s.p., destaques no original).

Ao mencionar a arrogância do direito, Villares, por meio de Roberto Lemos, toca na lógica jurídica de somar aspectos formais que sinalizam para a "integração" do indígena, como ter título de eleitor, ter conta bancária, dentre outros, para suprimir a existência dos mesmos na e da maneira como distintivamente podem viver em meio aos seus contextos englobados pela sociedade envolvente. Voltando aos acórdãos do TJMS, a negação da feitura da perícia antropológica também se apropria desta recorrência lógica, à medida que a imputabilidade penal do indígena é mensurada pela sua capacidade motora de pilotar uma moto ou de falar o idioma nacional.

\section{ARGUMENTOS QUE NEGAM A FEITURA DE PERÍCIA ANTROPOLÓGICA: AQUELE QUE MENSURA A CAPACIDADE MOTORA}

Sabino Benites foi capturado pelas teias do Judiciário e condenado a aproximados sete anos de prisão por ter roubado, no dia 16 de fevereiro de 2007, uma bicicleta e demais pertences, incluindo a soma de dez reais em dinheiro, de Sebastião Silvano (TJMS 2008). Seu advogado no processo, que recebeu a numeração 2008.021762-3/0000-00, contestou a primeira decisão, argumentando cerceamento de defesa pela falta de perícia antropológica e solicitou que todo o processo até então produzido pelo judiciário fosse anulado. O recheio de suas argumentações centra-se na autodeterminação, isto é, pelo simples fato de ser indígena o mesmo deve ter o acompanhamento de antropólogo para que este analise se os delitos praticados no município de Dourados - fora da reserva indígena - grosso modo são entendidos enquanto práticas desviantes para este indígena no contexto onde vive.

A desembargadora relatora, Marilza Lúcia Fortes, ao produzir seu voto quanto à alegação da ausência de perícia antropológica, o faz didaticamente. O primeiro passo é dado já anunciando que o indeferimento de "exame biopsicológico" é cabível "ainda mais no caso em tela", uma vez que

“[...] se trata de indígena aculturado e integrado à sociedade, que respondeu às perguntas formuladas pelas autoridades policial e judicial em 
português (f. 13-14, 73), trabalhava em fazenda, cortando cana-de-açúcar, possuindo rendimento mensal de $\mathrm{R} \$ 200,00$ (duzentos reais) (f. 16) o que lhe exige certo discernimento para se integrar à civilização" (TJMS 2008: s.p.).

Considerando as confusões entre perícia antropológica e biopsicológica, tal como expusemos no item anterior, levando-se em consideração os sentidos totalmente opostos que ambas assumem na contemporaneidade de produções antropológicas no Brasil, a julgadora aprofunda suas justificativas recortando e colando em sua sentença excertos de outros julgamentos que reiteram tal sinônimo, incluindo uma remissão a julgamento do Supremo Tribunal Federal (STF), sem a devida datação ou a mínima contextualização. Vejamos: "Se não existe dúvida sobre a sanidade mental do acusado, não há cogitar de cerceamento de defesa quando o juiz indefere a pretensão em decisão motivada" (TJMS 2008: s.p., itálicos no original).

Sem deixar dúvidas de que a perícia psicológica equivale à antropológica, logo após referenciar o STF, a magistrada retorna à mesma e superior corte brasileira com outro julgamento no qual a expressão "laudo antropológico" substitui o "exame de sanidade mental", quiçá para evitar repetições na escrita da sentença. Isto porque as demais jurisprudências voltam a enfatizar os exames de sanidade mental, dentre outras palavras que se ligam ao universo psicológico/psiquiátrico.

No término de seu voto, a julgadora faz menção ao Superior Tribunal de Justiça (STJ), quando nega o benefício constante no Estatuto do Índio, em parte ainda vigente à luz da Constituição Federal, de que o indígena condenado mude de regime prisional, passando da reclusão total para a semiliberdade. O final do julgamento sinaliza para a perda da identidade indígena, reiterando o projeto de colonização que previa a integração do indígena à comunhão nacional deixando de ser índio:

“1. O Estatuto do Índio só é aplicável ao indígena que ainda não se encontra integrado à comunhão e cultura nacional. 2. O indígena que está em pleno gozo de seus direitos civis, inclusive possuindo título de eleitor, está devidamente integrado à sociedade brasileira, logo, está sujeito às mesmas leis que são impostas aos demais cidadãos nascidos no Brasil. 3. O regime de semiliberdade não é aplicável ao indígena integrado à cultura brasileira. 4. O estabelecimento do regime inicial de cumprimento da pena deve observar não só o quantitativo da pena, porém a análise de todas as circunstâncias judiciais, considerada, ainda, eventual reincidência. 5. Se foi feito contra a conduta do réu rigorosa censurabilidade, justificado está o regime inicialmente fechado, necessário para reprovação do crime e ressocialização do apenado" (TJMS 2008: s.p., destaques no original). 


\section{CONCLUSÃO:}

\section{QUANDO DESDE O INÍCIO DA “HISTÓRIA” O INDÍGENA É NATIMORTO}

O que desejamos sublinhar no decorrer deste trabalho é a lógica jurídica como "engrenagem de moer gente", ${ }^{11}$ presente nos discursos legislativos que ampa(ra) ram a desconsideração de vozes destes sujeitos, o que não se confunde com a vitimização dos mesmos.

Portanto, negar a entrada da antropologia no contexto jurídico é distorcer propositadamente os eventos a partir dos quais os indígenas foram exterminados e reiterar as estratégias deste discurso enquanto disciplinar e autossuficiente na arena do judiciário (Foucault 1983, 2003). É vasta a literatura antropológica e histórica em solos brasileiros que retrata diferentes formas de etnocídio e genocídio praticados contra os indígenas, sendo que os que hoje sobrevivem resistem e não se omitem, tanto que estão na cena do judiciário respondendo criminalmente por seus atos - embora, por exemplo, sem terem direito a falar em sua língua materna, tal como a constituição prevê e lhes deve ser garantido, sobretudo no que diz respeito à tradução e ao direito a intérprete (Meyer e Becker 2012).

Finalizamos este trabalho nos reportando ao Joseph K. de O Processo de Kafka, na fala da psicanalista Fernanda Otoni de Barros, cujas análises sobre as consequências do processo na obra de Kafka e suas correlações com o aqui analisado (não) são meras coincidências:

"A responsabilidade é a condição da humanidade que nos habita. Quando K. ao final do processo grita: '- como um cão', sabemos que no fim, o sujeito foi subtraído da história, não foi dada a ele a chance de responder pela sua posição. Em todo e qualquer sistema de justiça, encontraremos vivo 'O processo' kafkaniano, pois não existe 'O processo' em condições de calcular o impensável que causa o sujeito em seu ato. Então, esta é a angústia que este processo produz. Contudo, se existe uma moral lacaniana, é aquela que orienta nunca deixar se levar sem o sujeito" (Barros 2007: 186).

Não por acaso, Carlos Frederico Marés de Souza Filho compara o conto kafkaniano Diante da Lei e o acesso à justiça pelos indígenas:

"Nada é mais dramaticamente parecido com a realidade dos direitos dos povos, escravos, índios, camponeses, mulheres e outros segmentos discriminados da sociedade latino-americana do que o conto de Kafka Diante da Lei. Um homem passa a vida inteira diante da porta da Lei esperando para entrar, sempre há um impedimento, uma ressalva, uma proibição momentânea, uma 
ameaça, até que o homem morre. [...] Assim os oprimidos quando chegam à porta da lei encontram um obstáculo, dificuldade, impedimento ou ameaça, mas o Estado e o Direito continuam afirmando que a porta está aberta, que a lei faz de todos os homens iguais, que as oportunidades, serviços e possibilidades de intervenção do Estado estão sempre presentes para todos, de forma isonômica e cega. [...]. O Estado e seu Direito não conseguem aceitar as diferenças sociais e as injustiças que elas engendram e na maior parte das vezes as omitem ou mascaram, ajudando em sua perpetuação" (Souza Filho 1994: 153).

Segundo Villares (2010: 27), a falta de decisões judiciais ou de entendimentos administrativos sobre o respeito aos sistemas jurídicos indígenas deriva das profundas diferenças de dois mundos: um mundo caracterizado por direitos escritos, formalidades, organismos competentes, dever de previsibilidade e que a todos alcança ou pretende alcançar por via do modelo iluminista à la Montesquieu; outro de tradição em regra diversa que não prevê a resolução de conflitos tal como nos impõe o poder judiciário na estrutura do Estado-nação brasileiro. O fato é que esses dois mundos se aproximam cada vez mais e caberá aos atores que produzem a cena do Direito Penal brasileiro colocá-los em diálogos, incluindo os antropólogos que cada vez mais produzem (academicamente ou não) na interface do direito e da antropologia.

\section{BIBLIOGRAFIA}

ALVAREZ, Marcos César, 2002, "A criminologia no Brasil ou como tratar desigualmente os desiguais", Dados: Revista de Ciências Sociais, 45 (4): 677-704.

AMORIM, Elaine, 2010, "A perícia antropológica no processo criminal: estudo de caso", em Luiz Fernando Villares (org.), Direito Penal e Povos Indígenas. Curitiba, Juruá Editora, 151-165.

AMORIM, Elaine, Kênia ALVES, e Marco Paulo Fróes SCHETTINO, 2010, "A ética na pesquisa antropológica no campo pericial", em Soraya Fleischer e Patrice Schuch (orgs.), Ética e Regulamentação na Pesquisa Antropológica. Brasília, Letras Livres/Editora UnB, 193$-216,<$ http://www.anis.org.br/arquivos_etica_antropologica.pdf $>$.

ARANTES, Rogério Bastos, 1999, “Direito e política: o Ministério Público e a defesa dos direitos coletivos", Revista Brasileira de Ciências Sociais (RBCS), 14 (39): 83-102.

BARATTA, Alessandro, 2002, Criminologia Crítica e Crítica do Direito Penal: Introdução à Sociologia do Direito Penal. Rio de Janeiro, Editora Revan (3. ${ }^{a}$ edição).

BARBOSA, Marco Antônio, 2001 , Direito Antropológico e Terras Indígenas no Brasil. São Paulo, Plêiade/Fapesp. 
BARROS, Fernanda Otoni de, 2007, "Atravessar as fronteiras, sem todo o processo", em Jacinto Nelson de Miranda Coutinho (org.), Direito e Psicanálise: Interseções a Partir de "O Processo" de Kafka. Rio de Janeiro, Editora Lumen Juris, 179-188.

BECKER, Howard S., 2008, Outsiders: Estudos de Sociologia do Desvio. Rio de Janeiro, Jorge Zahar Editor.

BECKHAUSEN, Marcelo Veiga, 2009, Questões de Cidadania e o Diálogo entre o Jurídico e a Antropologia, <http://www.ufrgs.br/naci/documentos/humanas_beckhausen.pdf> (acesso em 24/12/2012).

BOURDIEU, Pierre, 1998, A Economia das Trocas Lingüísticas: O que Falar Quer Dizer. São Paulo, Edusp (2. ${ }^{\mathrm{a}}$ edição).

BRASIL, 1941, Código de Processo Penal. Decreto-Lei n. ${ }^{\circ} 3689$ de 3 de outubro de 1941, $<$ http://www.planalto.gov.br/ccivil_03/Decreto-Lei/Del3689.htm> (acesso em: 21/7/201 1). BRASIL, 1973, Estatuto do Índio, Lei n. 6001 de 19 de dezembro de 1973, < http://www. funai.gov.br/quem/legislacao/estatuto_indio.html> (acesso em 21/12/2012).

BRASIL, 1988, Constituição da República Federativa do Brasil de 1988, <http://www.senado.gov. br/legislacao/const/con1988/CON1988_05.10.1988/CON1988.pdf> (acesso em 21/12/2012).

BRASIL, 2004, "Decreto n. ${ }^{\circ} 5051$ de 19 de abril de 2004: Promulga a Convenção n. ${ }^{\circ} 169$ da Organização Internacional do Trabalho - OIT sobre Povos Indígenas e Tribais", <http://www.planalto.gov.br/ccivil_03/_ato2004-2006/2004/decreto/d505 1.htm> (acesso em 26/11/2012).

BUTLER, Judith, 2004, Le pouvoir des mots: Politique du performatif. Paris, Éditions Amsterdam. CARRARA, Sérgio, 1998. Crime e Loucura: O Aparecimento do Manicômio Judiciário na Passagem do Século. Rio de Janeiro, Eduerj/Edusp.

CONJUR, 2009, "Mato Grosso do Sul é o estado com o maior número de índios encarcerados", <http://www.conjur.com.br/2009-jun-09/mato-grosso-sul-estado-maior-numero-indios -encarcerados $>$ (acesso em: 20/8/2010).

FOUCAUlT, Michel, 1983, Vigiar e Punir: Nascimento da Prisão. Petrópolis, RJ, Vozes.

FOUCAult, Michel, 2003, Eu, Pierre Rivière, Que Degolei Minha Mãe, Minha Irmã e Meu Irmão. Rio de Janeiro, Edições Graal (7. ${ }^{\text {a }}$ edição).

GEERTZ, Clifford, 1978, A Interpretação das Culturas. Rio de Janeiro, Zahar Editores.

LARAIA, Roque de Barros, 2003, Cultura: Um Conceito Antropológico. Rio de Janeiro, Jorge Zahar Editor (16. ${ }^{\mathrm{a}}$ edição).

LEITE, Ilka Boaventura, 2002, O Legado do Testamento: A Comunidade de Casca em Perícia. Florianópolis, UFSC/Nuer.

LEITE, Ilka Boaventura, 2005, "Os Laudos Periciais - um novo cenário na prática antropológica”, em Ilka Boaventura Leite (org.), Laudos Periciais Antropológicos em Debate. Florianópolis: Nuer/ABA, 15-28.

LENHARO, Alcir, 1986, "A terra para quem nela não trabalha: a especulação com a terra no Oeste brasileiro nos anos 50", Revista Brasileira de História, 6 (12): 47-64.

MEYER, Luiza, e Simone BECKER, 2012, "Reflexões sobre intérpretes judiciais para os Kaiowá à luz do caso Marcos Verón”, em Anais do I Congresso Jurídico dos Cursos de Direito da UFMS. Campo Grande, UFMS, CDRom.

NAÇÕES UNIDAS, 2011 , Declaração das Nações Unidas sobre os Direitos dos Povos Indígenas. Rio de Janeiro, Nações Unidas, <http://www.un.org/esa/socdev/unpfii/documents/DRIPS pt.pdf> (acesso em: 24/12/2012). 
NETO, Fernando da Costa Tourinho, 2002, "Os povos indígenas e as sociedades nacionais: conflito de normas e superação”, em André Lima (org.), O Direito para o Brasil Socioambiental. Porto Alegre, Sergio Antonio Fabris Editor, 189-229.

NUER (Núcleo de Estudos sobre Identidade e Relações Interétnicas), 2001, Laudos Antropológicos: Carta de Ponta das Canas. Florianópolis, Nuer/UFSC, col. Textos e Debates, n. ${ }^{\circ} 9$.

OLIVEIRA, João Pacheco de, 2010, "O nascimento do Brasil: revisão de um paradigma historiográfico”, Anuário Antropológico, 2009/1: 1 1-40.

OLIVEIRA, Jorge Eremites de, e Levi Marques PEREIRA, 2009, Nande Ru Marangatu: Laudo Pericial sobre Uma Terra Kaiowa na Fronteira do Brasil com o Paraguai, Município de Antônio João, Mato Grosso do Sul. Dourados, MS, Editora da UFGD.

OliveIRA, Jorge Eremites de, e Levi Marques PEREIRA, 2012, Terra Indígena Buriti: Perícia Antropológica, Arqueológica e Histórica sobre Uma Terra Terena na Serra de Macaraju, Mato Grosso do Sul. Dourados, MS, Editora da UFGD.

OliveIRA, Roberto Cardoso de, 2006, O Trabalho do Antropólogo. Brasília e São Paulo, Editora da Unesp (3. ${ }^{\mathrm{a}}$ edição).

PEIXOTO, Érica de Souza Pessanha, 2008, "Povos indígenas e o direito internacional dos direitos humanos", em Sidney Guerra e Lilian Balmant Emerique (orgs.), Direito das Minorias e Grupos Vulneráveis. Ijuí, RS, Editora Unijuí, 243-274.

PONTES, Bruno César Luz, 2010, "O índio e a justiça criminal brasileira”, em Luiz Fernando Villares (org.), Direito Penal e Povos Indígenas. Curitiba, Juruá Editora, 167-223.

ROCHA, Rodrigo Veras, 2008, "A ausência de Laudo Pericial Antropológico como causa de nulidade absoluta nos processos criminais em que o índio figure como réu", São José, Universidade do Vale de Itajaí, monografia para obtenção do grau de bacharel, < http://siaibib 01.univali.br/pdf/Rodrigo\%20Veras\%20Rocha.pdf> (acesso em 24/12/2012).

SANTOS FILHO, Roberto Lemos dos, 2011, "Cárcere privado praticado por indígenas: rejeição da denúncia por falta de prévio estudo antropológico”, Revista Jus Navigandi, fevereiro, <http://jus.com.br/revista/texto/18621/carcere-privado-praticado-por-indigenas -rejeicao-da-denuncia-por-falta-de-previo-estudo-antropologico > (acesso em 21/12/2012).

SCHWARCZ, Lilia Moritz, 1993, O Espetáculo das Raças: Cientistas, Instituições e Questão Racial no Brasil - 1870-1930. São Paulo, Companhia das Letras.

SOUZA FILHO, Carlos Frederico Marés de, 1994, "O direito envergonhado: o direito e os índios no Brasil”, em Luís Donisete Benzi Grupioni (org.), Índios no Brasil. Brasília, Ministério da Educação e do Desporto, 153-178.

SOUZA FILHO, Carlos Frederico Marés de, 2003, "Multiculturalismo e direitos coletivos", em Boaventura de Sousa Santos (org.), Reconhecer para Libertar: Os Caminhos do Cosmopolitismo Multicultural. Rio de Janeiro, Editora Civilização Brasileira, 7 1-110.

SOUZA, Estella Libardi de, 2008, "Povos indígenas e o Direito à diferença: do colonialismo jurídico à pluralidade de Direitos”, trabalho apresentado no Congresso Internacional de Pluralismo Jurídico e Direitos Humanos, Universidade Federal de Santa Catarina, Florianópolis, 20 a 22 de agosto de 2008, <http://www.nepe.ufsc.br/ controle/artigos/ artigo74.pdf $>$ (acesso em 24/12/2012).

TJMS (Tribunal de Justiça de Mato Grosso do Sul), 2007, "Recurso em sentido estrito n. ${ }^{\circ}$ 2007.03 1540-7/0000-00-Porto Murtinho. Rel. Des. João Batista da Costa Marques”, $<$ http://www.tjms.jus.br/cposg/pcpoResultadoConsProcesso2Grau.jsp? \&CDP=01000 4L070000\&nuProcesso $=2007.031540-7>($ acesso em 7/6/201 1$)$. 
TJMS (Tribunal de Justiça de Mato Grosso do Sul), 2008, "Apelação criminal n. 2008. 021762-3/0000-00-Dourados. Rel. Des ${ }^{a}$ Marilza Lúcia Fortes", <http://www.tjms.jus. $\mathrm{br} / \mathrm{cjosg} /$ pcjoDecisao.jsp? OrdemCodigo $=0 \&$ tpClasse $=J>($ acesso em: 24/12/2012).

VelHo, Gilberto, 1985, Desvio e Divergência: Uma Crítica da Patologia Social. Rio de Janeiro, Jorge Zahar Editor (8. ${ }^{\text {a }}$ edição).

VILLARES, Luiz Fernando, 2010, "Direito penal na ordem jurídica pluriétnica”, em Luiz Fernando Villares (org.), Direito Penal e Povos Indígenas. Curitiba, Juruá Editora, 15-27. WOlKMER, Antônio Carlos, 2008, História do Direito no Brasil. Rio de Janeiro, Forense (4. ${ }^{\mathrm{a}}$ edição).

YAMADA, Érika M., e Juliana G. BELLOQUE, 2010, "Plurarismo jurídico: direito penal, direito indígena e direitos humanos: uma análise do art. ${ }^{\circ} 121 .^{\circ}$ do Código Penal Brasileiro", em Luiz Fernando Villares (org.), Direito Penal e Povos Indígenas. Curitiba, Juruá Editora, 123-138.

ZAfFAroni, Raúl Eugênio, 2001, Em Busca das Penas Perdidas: A Perda da Legitimidade do Sistema Penal. Rio de Janeiro, Revan (5. ${ }^{\mathrm{a}}$ edição). 